\title{
$N$-Palmitoylethanolamine depot injection increased its tissue levels and those of other acylethanolamide lipids
}

This article was published in the following Dove Press journal:

Drug Design, Development and Therapy

9 August 2013

Number of times this article has been viewed

\author{
Stephanie L Grillo',* \\ Jantana Keereetaweep ${ }^{2, *}$ \\ Michael A Grillo' \\ Kent D Chapman² \\ Peter Koulen ${ }^{1-3}$ \\ 'Vision Research Center, Department \\ of Ophthalmology, School of Medicine, \\ University of Missouri - Kansas City, \\ Kansas City, MO, USA; ${ }^{2}$ University \\ of North Texas, Center for Plant \\ Lipid Research, Department of \\ Biological Sciences, Denton, TX, USA; \\ ${ }^{3}$ Department of Basic Medical Science, \\ School of Medicine, University of \\ Missouri - Kansas City, Kansas City, \\ MO, USA \\ *These authors contributed equally \\ to this work
}

\begin{abstract}
N$-Palmitoylethanolamine (NAE 16:0) is an endogenous lipid signaling molecule that has limited water solubility, and its action is short-lived due to its rapid metabolism. This poses a problem for use in vivo as oral administration requires a high concentration for significant levels to reach target tissues, and injection of the compound in a dimethyl sulfoxide- or ethanol-based vehicle is usually not desirable during long-term treatment. A depot injection of NAE 16:0 was successfully emulsified in sterile corn oil $(10 \mathrm{mg} / \mathrm{kg})$ and administered in young DBA $/ 2$ mice in order to elevate baseline levels of NAE 16:0 in target tissues. NAE 16:0 levels were increased in various tissues, particularly in the retina, 24 and 48 hours following injections. Increases ranged between $22 \%$ and $215 \%$ (above basal levels) in blood serum, heart, brain, and retina and induced an entourage effect by increasing levels of other 18 carbon $N$-Acylethanolamines (NAEs), which ranged between $31 \%$ and $117 \%$ above baseline. These results indicate that NAE 16:0 can be used as a depot preparation, avoiding the use of inadequate vehicles, and can provide the basis for designing tissue-specific dosing regimens for therapies involving NAEs and related compounds.
\end{abstract}

Keywords: cannabinoid receptor, vanilloid receptor, DBA/2 mice, lipid extraction, gas chromatography, mass spectrometry

\section{Introduction}

$N$-Acylethanolamines (NAEs) are endogenous lipid signaling molecules involved in numerous physiological functions in mammals, including neurotransmission and cellular protection. ${ }^{1}$ NAEs, including anandamide (NAE 20:4), an endogenous ligand of cannabinoid receptor 1 (CB1), are substrates of the fatty acid amide hydrolase (FAAH) enzyme. ${ }^{2,3} \mathrm{~N}$-Palmitoylethanolamine (NAE 16:0) is an NAE that has been shown to protect cells from oxidative stress ${ }^{4,5}$ and activate neuroprotective kinase signaling pathways, ${ }^{4}$ reduce myocardial infarct volume and neurological behavioral deficits in ischemic rats, ${ }^{6}$ provide substantial relief of objective and subjective symptoms of atopic eczema, ${ }^{7}$ decrease melanoma progression, ${ }^{8}$ and is reported to have anti-inflammatory properties. ${ }^{9}$ During in vivo studies, NAE 16:0 is rapidly metabolized by FAAH and, therefore, the action of NAE 16:0 is fairly short-lived, ${ }^{1}$ which poses a problem when administered orally. NAE 16:0 is a fatty acid amide which has very limited water solubility $^{1,9-11}$ and this is a major issue for in vitro and in vivo treatments, with dimethyl sulfoxide or ethanol vehicle required to dissolve NAE 16:0 at a rather low concentration of 20-25 mM. Often, then, the NAE 16:0 will precipitate out of solution when diluting into media or buffer if the final concentration is not low enough. This makes it difficult to determine a range for higher concentrations of NAE 16:0 in vitro or in vivo. Saline vehicles containing products such as polyethylene glycol, Tween $80,{ }^{12}$ or cyclodextrin 
in combination with ethano ${ }^{13}$ have also been used in order to aid solubility for single-dose in vivo administration of NAE 16:0, but NAE 16:0 has not yet been studied as a long-term dosing regimen.

Corn oil is commonly used as a vehicle to administer lipophilic, water-insoluble agents in vivo via gavage feeding, subcutaneous, intraperitoneal, or intramuscular injections. ${ }^{14}$ Oil-based depot injections are usually performed as an intramuscular or subcutaneous injection in order to achieve a slow and steady release of the compound. Radd et al performed release rate studies of haloperidol in corn oil and several other oils to test for an appropriate vehicle for depot injections (using fatty acids as solubilizers). ${ }^{15}$ Corn oil was shown to release haloperidol at a rate of $0.113 \mathrm{mg} / \mathrm{cm}^{2} / \mathrm{h}^{1 / 2}$ and was one of the slower releasing oils that were tested. ${ }^{15}$ Numerous studies use sterile corn oil for injection administration of highly lipophilic compounds, eg, steroid hormones, such as progesterone, ${ }^{16,17}$ and estradiol, ${ }^{16,18-20}$ and drugs such as tamoxifen, ${ }^{16,18-26}$ an estrogen receptor antagonist. The present study examines the effectiveness of NAE 16:0 as a depot injection, which allows for emulsification of the compound at a higher concentration in a corn oil preparation, to avoid precipitation problems. Furthermore, the depot injection of emulsified NAE 16:0 may represent a "slow-release" preparation for future experiments to study the effects of long-term treatments with lipid-soluble acylethanolamides on disease progression in mouse models of disease. For this study we have used young DBA/2 mice (Charles River Laboratories International, Inc, Wilmington, MA, USA), a mouse model of glaucoma, which are nonglaucomatous, to quantify baseline levels of NAE 16:0 in target tissues, and to measure the levels of NAE 16:0 levels in these tissues 24 and 48 hours after depot injections.

In this study, we show that basal levels of NAE 16:0 differ markedly in different tissues of young, non-glaucomatous $\mathrm{DBA} / 2$ mice and are particularly elevated in the retina. We also show that NAE 16:0 can be successfully emulsified into an oil depot injection for in vivo administration; the compound effectively reached the blood serum, heart, brain, and retina, and also induced an elevated entourage effect by increasing other acylethanolamide lipids, namely NAE 18:0, $18: 1,18: 2$, and 20:4.

\section{Materials and methods \\ Animals}

Ten 6-week-old male DBA/2 mice (16-21 g) were obtained from Charles River Laboratories and the mice were housed with five mice per cage. All animals had unlimited access to food and water and were maintained on a 12 hour light/ dark cycle. Animals were monitored on a daily basis with no reports of any weight or behavioral changes or pain or distress from the 24-48 hour treatment. All animal husbandry and experimental procedures were conducted in conformity with the Public Health Service Policy on Humane Care and Use of Laboratory Animals, performed in accordance with institutional guidelines and approved by the Institutional Animal Care and Use Committee (University of Missouri Kansas City, Kansas City, MO, USA).

\section{NAE 16:0 treatment}

Directly before treatment, NAE 16:0 compound (Best West Laboratories Inc, Salt Lake City, UT, USA) was ground using a mortar and pestle and emulsified in sterile corn oil by vortexing and ultrasonification at $37^{\circ} \mathrm{C}$ for 30 minutes. DBA/2 mice received a $100 \mu \mathrm{L}$ subcutaneous injection of either sterile corn oil (vehicle, $\mathrm{n}=4)$ or NAE 16:0 $(10 \mathrm{mg} / \mathrm{kg}$, based on a previous study ${ }^{6}$ ) and were sacrificed by $\mathrm{CO}_{2}$ asphyxiation at either $24(n=3)$ or $48(n=3)$ hours following injections. Blood serum was collected, heart, brain, and retina were dissected, snap-frozen in liquid nitrogen and stored at $-80^{\circ} \mathrm{C}$ in preparation for lipid extraction.

\section{Lipid extraction and NAE quantification}

Lipid extraction was as described previously. ${ }^{6}$ Briefly, the individual tissue samples were weighed (fresh weight [FW]) and homogenized in $2 \mathrm{~mL}$ hot 2-propanol $\left(70^{\circ} \mathrm{C}\right)$ and internal standards (50 ng each of D4-NAE 16:0 and D4-NAE 20:4 [Cayman Chemical Co, Ann Arbor, MI, USA]) were added. Samples were then incubated in a $70^{\circ} \mathrm{C}$ water bath for $30 \mathrm{~min}$ utes, following which, $1 \mathrm{~mL}$ of chloroform was added to each test tube and samples were vortexed and incubated at $4^{\circ} \mathrm{C}$ for overnight extraction. Monophasic lipid extracts were partitioned with $2 \mathrm{~mL}$ of $1 \mathrm{M} \mathrm{KCl}$. The lower organic phase was washed three additional times with $1 \mathrm{M} \mathrm{KCl}$ and subsequently dried to completion under argon. The total lipid mass (LM) was estimated gravimetrically and the samples were dissolved in chloroform and stored under argon at $-80^{\circ} \mathrm{C}$ until further purification by solid phase extraction (SPE). Silica SPE cartridges (100 mg, $1.5 \mathrm{~mL}$ [Supelco Analytical, Bellefonte, PA, USA]) were conditioned with $2 \mathrm{~mL}$ methanol, followed by $4 \mathrm{~mL}$ chloroform. Samples dissolved in $1 \mathrm{~mL}$ of chloroform were loaded onto SPE cartridges, followed by washing with $2 \mathrm{~mL}$ chloroform. NAEs were eluted with $2 \mathrm{~mL} \mathrm{1:1} \mathrm{(v/v)} \mathrm{ethyl}$ acetate:acetone, evaporated under nitrogen and derivatized in N,O-Bis(trimethylsilyl)trifluoroacetamide (BSTFA; Thermo Fisher Scientific, Waltham, MA, USA) for 30 minutes at 
$55^{\circ} \mathrm{C}$ (12). Derivatized samples were dried under nitrogen and redissolved in $50 \mu \mathrm{L} N$-hexane. TMS-ether derivatives of NAEs were identified via selective ion monitoring and quantified against internal standards (D4-NAE 16:0 and D4-NAE 20:4) by gas chromatography/mass spectrometry (model 7890 GC coupled with a 5975C mass selective detector [Agilent Technologies, Santa Clara, CA, USA]). ${ }^{27}$

\section{Statistical analysis}

Data was statistically analyzed using a one-way analysis of variance (ANOVA) with a Dunnett's or Bonferroni posttest when comparing within treatment groups or control data, respectively. Data are shown as mean \pm standard error of the mean.

\section{Results}

The highest basal levels of NAE 16:0 (nmol/g FW) were in the retina compared to blood serum $(P<0.001)$, heart $(P<0.001)$, and brain $(P<0.001$; Figure $1 \mathrm{~A})$. The same was true for metabolic data, that basal levels of NAE 16:0 (nmol/g LM) were highest in the retina compared to blood serum $(P<0.01)$, heart $(P<0.05)$, and brain $(P<0.001$; Figure 1B). Brain had the lowest levels of NAE 16:0 per $\mathrm{g}$ FW and LM, when compared to retina, heart $(P<0.05)$, and blood serum $(P<0.01$; Figure 1$)$.

NAE 16:0 levels were increased significantly over baseline in heart on a tissue weight basis after 24 hours $(P<0.05$; Figure 1A) and metabolically on a lipid weight basis after 48 hours $(P<0.001$; Figure 1B). NAE 16:0 per g brain tissue showed a sustained increase over 24 and 48 hours ( $P<0.05$ and FW, $P<0.05$, respectively; Figure 1A) and was increased per LM after 24 hours (Figure 1B). NAE 16:0 per $\mathrm{g}$ LM in retina significantly increased over baseline after 24 hours $(P<0.01$; Figure $1 \mathrm{~B})$.

NAE 18:0, 18:1, 18:2, and 20:4 were also increased in some tissues following the NAE 16:0 depot injection (Figure 2). Levels of NAE 18:0 in blood serum $(P<0.001)$, heart $(P<0.01)$, brain $(P<0.05)$, and retina $(P<0.01)$ were raised after 24 hours (Figure 2 ) and sustained in heart after 48 hours $(P<0.05$; Figure $2 \mathrm{~B})$. Levels of 18:1 in blood serum $(P<0.01)$ and retina $(P<0.05)$ were elevated after 24 hours and levels in the retina further increased after 48 hours $(P<0.01$; Figure $2 \mathrm{~A}$ and D). Levels of 18:2 were above detection levels in heart and retina only. Levels of 18:2 in retina were significantly raised after 24 hours $(P<0.05$; Figure 2D). NAE 20:4 levels in brain $(P<0.05)$ and retina $(P<0.05)$ were increased after 24 hours and the retina sustained increased levels over 48 hours $(P<0.05$; Figure 2C and D).
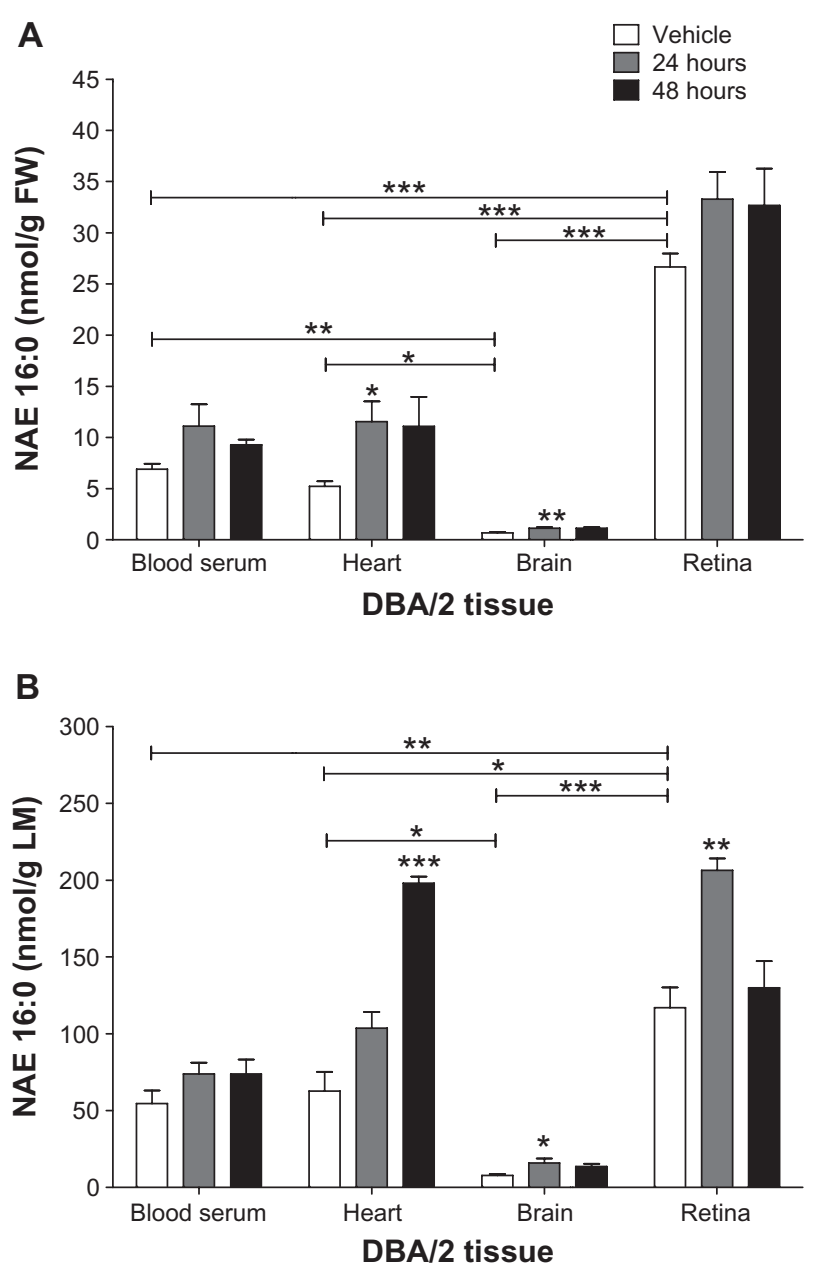

Figure I Comparison of control levels of NAE 16:0 in various tissues of DBA/2 mice.

Notes: (A) Functional or (B) metabolic effect of depot injections 24 and 48 hours following administration, showing NAE 16:0 levels per g FW or g LM, respectively. Data within treatment groups or comparing control levels (bars) were statistically analyzed using a one-way ANOVA with a Dunnett's or Bonferroni posttest, respectively. Data represented as Mean \pm standard error of the mean, $n=3-4$. $* P<0.05$, *** $<<0.01$, *** $P<0.001$.

Abbreviations: FW, fresh weight; LM, lipid mass; NAE 16:0, N-Palmitoylethanolamine.

\section{Discussion}

NAEs are lipid signaling molecules that are present in the central nervous system (CNS). The present study measures the levels of NAEs in blood serum, heart, brain, and retina of DBA/2 mice in the absence or presence of NAE 16:0, administered as an oil-based depot injection.

DBA/2 mice showed higher levels of all NAEs in blood serum when compared to other mouse strains and species. ${ }^{1,28-30}$ Levels of NAE 16:0 and 18:1 were higher in the DBA/2 heart when compared to other mouse strains, ${ }^{31,32}$ however, lower levels of NAE 20:4 were measured. Brain levels of all NAEs were lower in the DBA/2 mice when compared to other mouse strains and species. ${ }^{31,33}$ Very low 
A

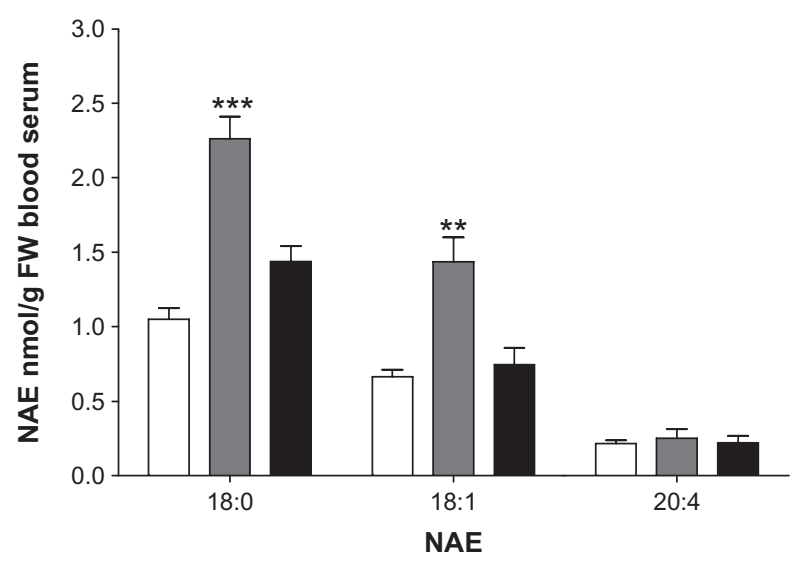

C

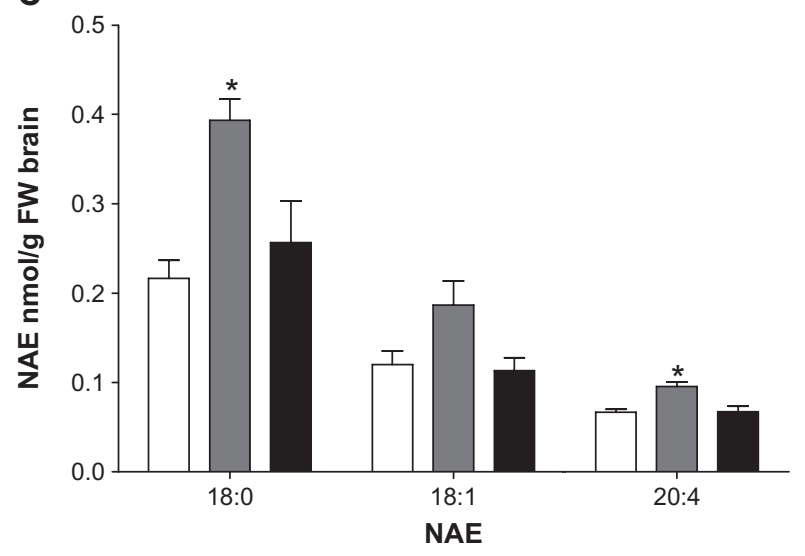

B

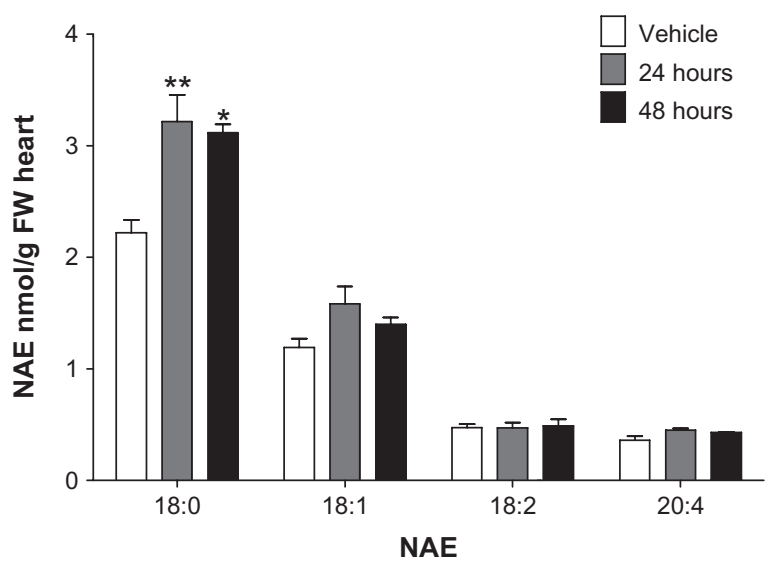

D

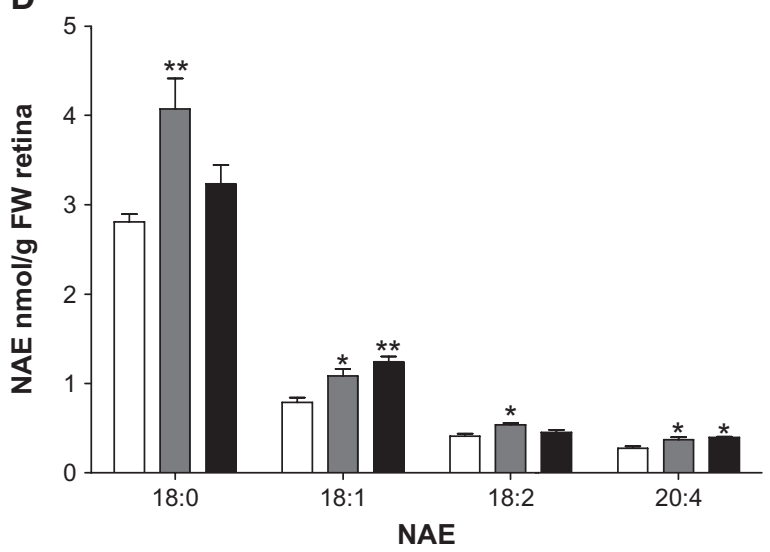

Figure 2 Elevation above control levels of NAE 18:0, 18:1, 18:2, and 20:4, 24 and 48 hours following NAE 16:0 depot injection.

Notes: Depot injection in (A) blood serum, (B) heart (C) brain, and (D) retina of DBA/2 mice. Data were statistically analyzed using a one-way analysis of variance (ANOVA) with a Dunnett's post test. $* P<0.05$, **P $<0.01$. Mean \pm standard error of the mean, $\mathrm{n}=3-4$.

Abbreviations: FW, fresh weight; NAE, N-Acylethanolamine; NAE 16:0, N-Palmitoylethanolamine.

basal levels of NAE 18:2 have been reported in the brain at $\sim 2 \mathrm{pmol} / \mathrm{g} \mathrm{FW}^{34}$ and were not detected in this study. NAE 16:0 was much higher in the retina of $\mathrm{DBA} / 2$ mice compared to human retina, ${ }^{35,36}$ but NAE 20:4 had similar retina levels to humans. ${ }^{35,36}$ These variations in values could be due to differences in species or mouse strain, but are also likely due to differences in extraction and detection measures between various studies.

NAE 16:0 was increased above baseline in serum and heart by $61 \%$ and $119 \%$ after 24 hours, respectively, and, after 48 hours, NAE $16: 0$ was increased by $215 \%$ per total LM in heart tissue. Per LM, NAE 16:0 levels were significantly increased by $106 \%$ and $77 \%$ in brain and retina after 24 hours, respectively, and a $63 \%-65 \%$ and a $22 \%-25 \%$ increase was sustained over a 48 hour period per g FW, respectively. Additionally, we showed that the NAE 16:0 depot injection induced an entourage effect of other NAEs. Levels of NAE 18:0 were significantly increased by $45 \%-115 \%$ in all tissues after 24 hours, and the heart sustained increased NAE 18:0 levels of $40 \%-45 \%$ over the 48 hour period. NAE 18:1 was increased in blood serum and retina after 24 hours by $117 \%$ and $38 \%$, respectively, and levels were further increased by $20 \%$ in the retina 48 hours following the depot injection. NAE 18:2 was only detected in heart and retina, and levels were unchanged in heart but increased by $31 \%$ in retina after 24 hours. NAE 20:4 was significantly increased in brain after 24 hours, and the retina sustained a $33 \%-43 \%$ increase over 48 hours.

NAE 20:4 and other polyunsaturated NAEs exert biological activity by binding to cannabinoid receptors (CB) ${ }^{37} \mathrm{CB} 1$ is found distributed throughout the CNS and various tissue ${ }^{38}$ whereas CB2 is mainly found in the immune system, retina, and CNS. ${ }^{39}$ NAE 20:4 is also a full agonist for the vanilloid receptor 1 (VR1), an ionotropic cation channel expressed in the peripheral sensory system as well as in the CNS, and acts as nociceptor transducer. ${ }^{40}$ NAEs with 18 carbon atom acyl 
chains (NAE 18:0, 18:1, and 18:2) are thought to be potential modulators of VR $1 .{ }^{41-43}$ There is some discussion that NAE 16:0 may act directly on an unidentified $\mathrm{CB}$ receptor or be a positive allosteric modulator of the VR1 receptor, ${ }^{40,44}$ or that NAE 16:0-mediated neuroprotection is thought to act by reducing apoptotic and inflammatory pathways, independent of $\mathrm{CB}$ and VR1 activation. ${ }^{37,45,46}$ NAE 16:0 is thought to be an 'entourage' compound for NAE 20:4, which enhances its biological actions, possibly by competing with NAE 20:4 for FAAH, thereby reducing anandamide hydrolysis and increasing anandamide levels consequently, increasing $\mathrm{CB}$ receptor activation, ${ }^{44}$ or by increasing the affinity of NAE 20:4 for receptors. ${ }^{44}$ Long-term treatment with NAE 16:0, in vitro, was shown to downregulate FAAH. ${ }^{40}$ Therefore, it is possible that long-term NAE 16:0 administration could simulate the downregulation of FAAH, thus increasing endogenous NAEs, including NAE 20:4, to elicit protection from neurodegeneration in chronic diseases, as well as exerting neuroprotective effects through apoptotic and inflammatory pathways.

\section{Conclusion}

This study has shown that NAE 16:0 can be successfully emulsified into an oil depot injection for in vivo administration, eliminating the use of gavage feeding and allowing for a safer vehicle to be administered in vivo, by bypassing the solubility difficulties with NAE 16:0 and eliminating the use of vehicles such as ethanol and dimethyl sulfoxide, which are inadequate for long-term studies. Also, depot injections allow for fewer injections and a steady slow-release of the compound, which can be maintained if studying long-term NAE 16:0 dosing and its effect over time. We also have shown that NAE 16:0, administered as a subcutaneous depot injection, effectively reaches the blood serum, heart, brain, and retina and can induce an elevation in the tissue content of other NAEs. Overall, this study allows for the long-term administration of NAE 16:0, which can induce elevated levels of other NAEs, either by inhibiting the FAAH enzyme or via alternative routes, for in vivo experiments targeting the protection of tissues from acute or chronic degeneration such as in neuroprotection. ${ }^{4,39}$

\section{Acknowledgments}

Research reported in this publication was supported in part by grants from the National Eye Institute (EY014227 and EY022774), the Institute on Aging (AG010485, AG022550 and AG027956), the National Center for Research Resources, and National Institute of General Medical Sciences (RR022570 and RR027093) of the National Institutes of
Health (PK). The content is solely the responsibility of the authors and does not necessarily represent the official views of the National Institutes of Health. Additional support by a Fight for Sight Post-Doctoral Award (SLG) and the Felix and Carmen Sabates Missouri Endowed Chair in Vision Research, the Vision Research Foundation of Kansas City, and a Challenge Grant from Research to Prevent Blindness $(\mathrm{PK})$ is gratefully acknowledged. Acylethanolamide analysis by gas chromatography/mass spectrometry was made possible through a supplemental instrument award to KDC from United States Department of Energy, Office of Basic Energy Sciences (BES grant number DE-FG02-05ER15647).

\section{Disclosure}

The authors report no conflicts of interest in this work.

\section{References}

1. Lambert DM, Vandevoorde S, Jonsson KO, Fowler CJ. The palmitoylethanolamide family: a new class of anti-inflammatory agents? Curr Med Chem. 2002;9(6):663-674.

2. Jian W, Edom R, Weng N, Zannikos P, Zhang Z, Wang H. Validation and application of an LC-MS/MS method for quantitation of three fatty acid ethanolamides as biomarkers for fatty acid hydrolase inhibition in human plasma. J Chromatogr B Analyt Technol Biomed Life Sci. 2010;878(20):1687-1699.

3. Day TA, Rakhshan F, Deutsch DG, Barker EL. Role of fatty acid amide hydrolase in the transport of the endogenous cannabinoid anandamide. Mol Pharmacol. 2001;59(6):1369-1375.

4. Duncan RS, Chapman KD, Koulen P. The neuroprotective properties of palmitoylethanolamine against oxidative stress in a neuronal cell line. Mol Neurodegener. 2009;4:50.

5. Lombardi G, Miglio G, Varsaldi F, Minassi A, Appendino G. Oxyhomologation of the amide bond potentiates neuroprotective effects of the endolipid N-palmitoylethanolamine. J Pharmacol Exp Ther. 2007;320(2):599-606.

6. Kilaru A, Tamura P, Garg P, et al. Changes in N-acylethanolamine Pathway Related Metabolites in a Rat Model of Cerebral Ischemia/ Reperfusion. J Glycom Lipidom. 2010;1(1):101.

7. Eberlein B, Eicke C, Reinhardt HW, Ring J. Adjuvant treatment of atopic eczema: assessment of an emollient containing N-palmitoylethanolamine (ATOPA study). J Eur Acad Dermatol Venereol. 2008;22(1):73-82.

8. Hamtiaux L, Masquelier J, Muccioli GG, et al. The association of N-palmitoylethanolamine with the FAAH inhibitor URB597 impairs melanoma growth through a supra-additive action. BMC Cancer. 2012;12:92.

9. Ueda N, Yamanaka K, Yamamoto S. Purification and characterization of an acid amidase selective for N-palmitoylethanolamine, a putative endogenous anti-inflammatory substance. J Biol Chem. 21, 2001;276(38):35552-35557.

10. Vandevoorde S, Jonsson K-O, Fowler CJ, Lambert DM. Modifications of the Ethanolamine Head in N-Palmitoylethanolamine: Synthesis and Evaluation of New Agents Interfering with the Metabolism of Anandamide. J Med Chem. 2003;46(8):1440-1448.

11. Facci L, Dal Toso R, Romanello S, Buriani A, Skaper SD, Leon A. Mast cells express a peripheral cannabinoid receptor with differential sensitivity to anandamide and palmitoylethanolamide. Proc Natl Acad Sci U SA. 1995;92(8):3376-3380.

12. Citraro R, Russo E, Scicchitano F, et al. Antiepileptic action of N-palmitoylethanolamine through CB1 and PPAR- $\alpha$ receptor activation in a genetic model of absence epilepsy. Neuropharmacology. 2013;69: $115-126$. 
13. García MdC, Adler-Graschinsky E, Celuch SM. Enhancement of the hypotensive effects of intrathecally injected endocannabinoids by the entourage compound palmitoylethanolamide. Eur J Pharmacol. 2009;610(1-3):75-80.

14. Geng X-C, Li B, Zhang L, et al. Corn oil as a vehicle in drug development exerts a dose-dependent effect on gene expression profiles in rat thymus. J Appl Toxicol. 2012;32(10):850-857.

15. Radd BL, Newman AC, Fegely BJ, Chrzanowski FA, Lichten JL, Walkling WD. Development of haloperidol in oil injection formulations. J Parenter Sci Technol. 1985;39(1):48-51.

16. Lemini $\mathrm{C}$, Medina $\mathrm{M}$, Avila ME, et al. In vivo and in vitro evaluation of the estrogenic properties of the 17beta-(butylamino)-1,3,5(10)estratrien-3-ol (buame) related to 17beta-estradiol. Pharmacol Rep. 2012;64(4):940-950.

17. Fadem BH. Evidence for extended action of gonadal hormones on the organization of sexually dimorphic behavior and morphology in gray short-tailed opossums (Monodelphis domestica). Horm Behav. 2001;39(2):113-120.

18. Jaccoby S, Arnon E, Snapir N, Robinzon B. Effects of estradiol and tamoxifen on feeding, fattiness, and some endocrine criteria in hypothalamic obese hens. Pharmacol Biochem Behav. 1995;50(1):55-63.

19. Castellano-Díaz E, Gonzalez-Quijano MI, Liminana JM, Díaz-Chico BN. Tamoxifen decreases the estradiol induced progesterone receptors by interfering with nuclear estrogen receptor accumulation. J Steroid Biochem. 1989;33(1):133-139.

20. Jaccoby S, Pinchasov Y, Snapir N, Robinzon B. Hypothalamic obese, functionally castrated hens are hypersensitive to estrogenic modulation of lipid metabolism. Physiol Behav. 1996;60(3):913-918.

21. Hensler M, Bardova K, Jilkova ZM, et al. The inhibition of fat cell proliferation by n-3 fatty acids in dietary obese mice. Lipids Health Dis. 2011;10:128.

22. Reinert RB, Kantz J, Misfeldt AA, et al. Tamoxifen-induced cre-loxp recombination is prolonged in pancreatic islets of adult mice. PloS One. 2012;7(3):e33529.

23. Riopel MM, Li J, Liu S, Leask A, Wang R. $\beta 1$ integrin-extracellular matrix interactions are essential for maintaining exocrine pancreas architecture and function. Lab Invest. 2013;93(1):31-40.

24. Tong S, Chen Q, Shan SQ, Dewhirst MW, Yuan F. Quantitative comparison of the inhibitory effects of GW5638 and tamoxifen on angiogenesis in the cornea pocket assay. Angiogenesis. 2006;9(2):53-58.

25. Kim DJ, Han BS, Ahn B, Lee KK, Kang JS, Tsuda H. Promotion potential of tamoxifen on hepatocarcinogenesis in female SD or F344 rats initiated with diethylnitrosamine. Cancer Lett. 1996;104(1):13-19.

26. Gao S, Singh J. In vitro percutaneous absorption enhancement of a lipophilic drug tamoxifen by terpenes. J Control Release. 1998; 51(2-3):193-199.

27. Venables BJ, Waggoner CA, Chapman KD. N-acylethanolamines in seeds of selected legumes. Phytochemistry. 2005;66(16):1913-1918.

28. Hill MN, Miller GE, Carrier EJ, Gorzalka BB, Hillard CJ. Circulating endocannabinoids and $\mathrm{N}$-acyl ethanolamines are differentially regulated in major depression and following exposure to social stress. Psychoneuroendocrinology. 2009;34(8):1257-1262.

29. Caraceni P, Viola A, Piscitelli F, et al. Circulating and hepatic endocannabinoids and endocannabinoid-related molecules in patients with cirrhosis. Liver Int. 2010;30(6):816-825.

30. Sipe JC, Scott TM, Murray S, et al. Biomarkers of endocannabinoid system activation in severe obesity. PLoS One. 2010;5(1):e8792.

Drug Design, Development and Therapy

\section{Publish your work in this journal}

Drug Design, Development and Therapy is an international, peerreviewed open-access journal that spans the spectrum of drug design and development through to clinical applications. Clinical outcomes, patient safety, and programs for the development and effective, safe, and sustained use of medicines are a feature of the journal, which
31. Kilaru A, Isaac G, Tamura P, et al. Lipid profiling reveals tissue-specific differences for ethanolamide lipids in mice lacking fatty acid amide hydrolase. Lipids. 2010;45(9):863-875.

32. Piscitelli F, Carta G, Bisogno T, et al. Effect of dietary krill oil supplementation on the endocannabinoidome of metabolically relevant tissues from high-fat-fed mice. Nutr Metab (Lond). 2011;8(1):51.

33. Maccarrone M, Attinà M, Bari M, Cartoni A, Ledent C, Finazzi-Agrò A. Anandamide degradation and $\mathrm{N}$-acylethanolamines level in wildtype and CB1 cannabinoid receptor knockout mice of different ages. J Neurochem. 2001;78(2):339-348.

34. Artmann A, Petersen G, Hellgren LI, et al. Influence of dietary fatty acids on endocannabinoid and $\mathrm{N}$-acylethanolamine levels in rat brain, liver and small intestine. Biochim Biophys Acta. 2008;1781(4):200-212.

35. Matias I, Wang JW, Moriello AS, Nieves A, Woodward DF, Di Marzo V. Changes in endocannabinoid and palmitoylethanolamide levels in eye tissues of patients with diabetic retinopathy and age-related macular degeneration. Prostaglandins Leukot Essent Fatty Acids. 2006;75(6): 413-418.

36. Chen J, Matias I, Dinh T, et al. Finding of endocannabinoids in human eye tissues: implications for glaucoma. Biochem Biophys Res Commun. 2005;330(4):1062-1067.

37. Berdyshev EV, Schmid PC, Krebsbach RJ, et al. Cannabinoid-receptorindependent cell signalling by $\mathrm{N}$-acylethanolamines. Biochem $\mathrm{J}$. 2001;360(Pt 1):67-75.

38. Yazulla S, Studholme KM, McIntosh HH, Fan SF. Cannabinoid receptors on goldfish retinal bipolar cells: electron-microscope immunocytochemistry and whole-cell recordings. Vis Neurosci. 2000;17(3):391-401.

39. Lu Q, Straiker A, Maguire G. Expression of CB2 cannabinoid receptor mRNA in adult rat retina. Vis Neurosci. 2000;17(1):91-95.

40. De Petrocellis L, Bisogno T, Ligresti A, Bifulco M, Melck D, Di Marzo V. Effect on cancer cell proliferation of palmitoylethanolamide, a fatty acid amide interacting with both the cannabinoid and vanilloid signalling systems. Fundam Clin Pharmacol. 2002;16(4):297-302.

41. Movahed P, Jonsson BA, Birnir B, et al. Endogenous unsaturated C18 N-acylethanolamines are vanilloid receptor (TRPV1) agonists. J Biol Chem. 2005;280(46):38496-38504.

42. Parolaro D, Massi P, Rubino T, Monti E. Endocannabinoids in the immune system and cancer. Prostaglandins Leukot Essent Fatty Acids. 2002;66(2-3):319-332.

43. Zimov S, Yazulla S. Localization of vanilloid receptor 1 (TRPV1/VR1)like immunoreactivity in goldfish and zebrafish retinas: restriction to photoreceptor synaptic ribbons. J Neurocytol. 2004;33(4):441-452.

44. Ho WS, Barrett DA, Randall MD. 'Entourage' effects of $\mathrm{N}$-palmitoylethanolamide and $\mathrm{N}$-oleoylethanolamide on vasorelaxation to anandamide occur through TRPV1 receptors. Br J pharmacol. 2008; 155(6):837-846.

45. Garg P, Duncan RS, Kaja S, Koulen P. Intracellular mechanisms of $\mathrm{N}$-acylethanolamine-mediated neuroprotection in a rat model of stroke. Neuroscience. 2010;166(1):252-262.

46. Duncan RS, Xin H, Goad DL, Chapman KD, Koulen P. Protection of Neurons in the Retinal Ganglion Cell Layer against Excitotoxicity by the N-Acylethanolamine, Linoleoylethanolamine. Clin Ophthalmol. 2011;5:543-548.

has also been accepted for indexing on PubMed Central. The manuscript management system is completely online and includes a very quick and fair peer-review system, which is all easy to use. Visit http://www.dovepress.com/testimonials.php to read real quotes from published authors.

Submit your manuscript here: http://www.dovepress.com/drug-design-development-and-therapy-journal 